\title{
Changing relationship seen in new corporate-university ties
}

\section{Boston}

Du PONT Electronics last week publicly unveiled a fledgling $\$ 1.5$ million university/industry programme with 12 institutions including the Massachusetts Institute of Technology (MIT), Syracuse University and the University of Arizona. A spokesman for the 'Research Alliance' programme proclaimed that Du Pont had "hired schools to work as an extension of the company's R\&D staff", a description that displeases some academics.

Du Pont's programme involves approximately 15 individual projects ranging in scale from $\$ 50,000$ to $\$ 150,000$

\section{Industry calls for review of teaching}

\section{London}

IN the distribution of resources among UK universities, there should be less emphasis on the quality of research and more on the quality of teaching, according to a pressure group of university vice-chancellors and company chairmen, the Council for Industry and Higher Education. In a response last week to the exercise being carried out by the Universities Grants Committee (UGC) to evaluate research, the council says that industry values teaching above research, and it urges the UGC to carry out a review of teaching similar to that for research. In industry, there is "widespread and often passionate concern" about teaching, says the council, and a review "which seems to judge universities' resourceworthiness by their research prowess only, gives just the wrong emphasis".

But the UGC rejects the criticism outright. The review of research is only one of many assessments carried out by the UGC and teaching is evaluated, says a spokesman. "That criticism is idiotic."

The council also criticizes the research review itself. Although it accepts that the review is necessary, it stresses that it should not be based simply on the volume or value of a department's research contracts, as this would lead to a bias towards applied work which is easier to "sell", and companies do not support this shift.

It also warns that the review might produce a three-tier structure of universities which would be "unnecessarily rigid" and would damage morale and the quality of teaching. But the UGC says the criticisms are ill-conceived and invalid. Research is not evaluated solely on the merit of research contracts, and a three-tier structure may not emerge from the review process, says a spokesman.

Christine McGourty and involving among other things optoelectronics, thermal conductivity and computer-aided design of electronic circuitry. The programme is an example of many similar new corporate/university arrangements which move away from open-ended 'no-strings-attached' research grants towards more directed research. Noting that US universities used to "remain aloof" from such directed research arrangements with corporations, Dr Rudy Carboni, director of Du Pont's Research Alliance, says the programme's existence is an indication of a "very, very big change in the climate at American universities".

With federal dollars accounting for less total university research spending, universities have turned increasingly to corporate support. At MIT, for example, Carol Van Akin, director of the Office of Sponsored Research, calls industrially funded research the school's "most significant growth area in funding". Industry funding at MIT has risen 20 per cent annually since 1976 and now totals about 15 per cent of all money spent on research at the school.

This has led to an increasingly entrepreneurial atmosphere in academic departments. Carboni and many others praise the changes as a key strategy to bring products to market quickly in fast-paced, high-technology fields and keep the United States competitive with Japan and other countries. But others have reservations. Sheldon Krimsky, philosopher of science at Tufts University, believes that some of the new arrangements threaten to skew research priorities. Krimsky stresses the "different rules" that guide research in industry and academic life.

Du Pont's Research Alliance is just one of many such arrangements in the newly evolving relationship between industry and academic life in the United States. In late 1986, Washington University caused raised eyebrows when it became the first university to go into business, forming its own private marketing arm in a joint venture with a subsidiary of Monsanto. In the arrangement, the new corporate/ university entity would help university researchers to commercialize and market biomedical and other high-technology products that came from their research.

Carboni says that Du Pont's programme is a more personalized effort than many previous arrangements in that the company tailors the projects directly to selected academic researchers. But Carboni acknowledges the highly directed nature of the research. "This research is not funded by an unrestricted grant", he notes. "Researchers have to stay within the agreed-upon objectives." Seth Shulman

\section{Fault in Indian communications satellite not worth repairing}

\section{New Delhi}

THE Indian Space Research Organization (ISRO) has decided to abandon its efforts to repair the fault in the INSAT-1C satellite which was launched on 21 July. The $\$ 140$-million satellite has been crippled by "a massive short circuit" in one of the two power buses. That means only half the planned power is available for operating the television, telecommunications and meteorological payloads.

For more than four weeks, scientists from ISRO and the American Ford Aero space Corporation (FAC), which built the spacecraft, have been carrying out simulations on the ground to find a fault clearance plan. It became evident that repairing INSAT-1C carried a risk of losing even the limited services the satellite can now provide. ISRO has thus found it "prudent" to keep the spacecraft in its present condition "rather than risk corrective measures that may or may not succeed".

According to space commission chairman Professor U. R. Rao, repairs will be attempted only if a crisis threatens the survival of the spacecraft. The satellite can at present handle 2,000 telephone calls (instead of 4,000) and one television pro- gramme (instead of two). The power failure will not affect on the ability of the satellite to send pictures of cloud cover.

More serious, according to ISRO, is the problem of maintaining the thermal balance of the satellite consequent to the loss of one electrical bus - a problem that will be accentuated during the satellite eclipse seasons. The spacecraft has also lost the redundancies in vital subsystems such as telemetry, telecommand, and attitude and orbit control systems. Should any of these systems develop problems, the satellite will become useless.

According to ISRO, INSAT-1C has been insured for $\$ 72.6$ million at a premium of $\$ 11.05$ million. The insurance claims will be lodged after the stipulated period of 180 days.

It is not the first time ISRO has had problems with satellites manufactured by FAC. INSAT-1A failed within three months after launch in 1982, and its successor INSAT-1B had difficulties in unfurling the solar panels and the solar sail. These design defects were corrected in INSAT-IC but, according to Rao, no one expected it to develop a fault in its power supply.

K. S. Jayaraman 